\title{
Quantification of XRCC and DNA-PK proteins in cancer cell lines and human tumors by LC-MS/MS
}

Background: The x-ray repair cross-complementing (XRCC) proteins and a catalytic subunit of nuclear DNA-dependent serine/threonine protein kinase (DNA-PK) play important roles in cancer biology. Understanding the protein expression levels allows us to reconstruct in vivo functionality and to qualify protein biomarkers. Methods \& results: XRCC and DNA-PK proteins in human cancer cells and tumor tissues have been identified and quantified by selected peptides using NanoLC and highresolution mass spectrometry. The stable isotope-labeled full-length protein XRCC4 $\left(\left[{ }^{13} \mathrm{C}_{6},{ }^{15} \mathrm{~N}_{4}\right]\right.$-arginine and $\left[{ }^{13} \mathrm{C}_{6},{ }^{15} \mathrm{~N}_{2}\right]$-lysine) uses as the internal standard. Conclusion: The assay range is $0.140-450 \mathrm{fmol}$ (coefficient of variation: $25 \%$ ) for XRCC4 in bovine serum albumen. The quantitative protein expression levels for XRCC and DNA-PK in HeLa, Ramos and HEK-293 cells and tumor tissues (lung and lymphoma) are reported.

\section{Background}

Quantitative proteomic MS analysis of biological samples focuses on identifying the proteins present and establishing the abundance of those proteins in the samples [1-3]. The ability to quantify properly identified proteins in biological samples in a comprehensive fashion engenders an enhanced understanding of cellular behavior during development or in response to disease, and can lead to novel biomarker and target discoveries [4-6]. Developing more accurate and cost-effective methods to quantify target proteins and biomarkers has recently garnered increased effort. There are at least three methods of quantifying proteins via MS:

- Stable isotope labeling of amino acids in cell culture, which can correct for losses during sample extraction or variability in chromatographic separation and ionization efficiency [7-10];

- Label-free approaches that are based on counting spectra/peptide numbers or utilizing fragment ion intensities as a surrogate for expression level [11,12]. The label-free approach can be particularly useful when identifying unique biomarkers based on comparative analysis of clinical samples collected across multiple sites over extended time periods [13];

- An additional option is to use isotopelabeled, full-length proteins as IS spiked in at the beginning of sample processing to account for sample preparation and analytical variation [14]. Significant advances have been demonstrated based on isotope-labeled, full-length proteins as IS [14].

In particular, the processes of digestion, enrichment and immunoaffinity removal of abundant proteins can be highly variable, and have been associated with poor precision. As noted by Diamandis, a lack of proper biomarker analytical method validation can lead to the generation of data that could be highly misleading $[15,16]$ confounding studies intended to compare the concentration of a protein across different samples [17]. However, bearing in mind the thousands of proteins in numerous biological networks, the cost and preparation time of isotope-labeled full-length proteins should be considered as using labeled protein IS for all interesting protein targets may be implacable.
Matthew V Myers', Stephen E Maxwell ${ }^{1}$ \& Xiaomin Wang ${ }^{*, 1}$

${ }^{1}$ Celgene Corporation, Summit, NJ 07901, USA

*Author for correspondence: xwang@celgene.com 


\section{Key terms}

Biomarker analytical method validation: During drug development, biomarkers can be used for a wide variety of purposes; therefore, a fit-for-purpose approach should be used for assay qualification. When the biomarker data will be used to support regulartory actions (i.e., safety, effectiveness), the analytical assay should be fully validated.

Protein kinase: Enzyme that modifies other proteins by chemically adding phosphate groups to them (phosphorylation). Phosphorylation usually results in a functional change of the target protein (substrate) by changing enzyme activity, cellular location or association with other proteins.

Stable isotope-labeled full-length protein: Protein of identical amino acid sequence in which ideally three or more atoms have been replaced with ${ }^{13} \mathrm{C},{ }^{15} \mathrm{~N}$ or a combination of both (i.e., $\left[\mathrm{U}-{ }^{13} \mathrm{C}_{6},{ }^{15} \mathrm{~N}_{4}\right]$-L-arginine and $\left[\mathrm{U}-{ }^{13} \mathrm{C}_{6},{ }^{15} \mathrm{~N}_{2}\right]$-L-lysine)

Cancer cell lines: Most commonly used human cancer cell lines, for example, HeLa and HEK-293 were derived from cervical and kidney cancer cells, respectively. The cell lines were found to be remarkably durable and prolific as illustrated by the contamination of many other cell lines used in research.

The x-ray repair cross-complementing (XRCC1, 2, 3, 4, 5 and 6 ) genes encode crucial scaffold proteins that are closely associated with the base excision repair pathway [18]. XRCC1, XRCC4, XRCC5 and XRCC6 are different proteins, which belong to the XRCC family of proteins. The XRCC family of proteins plays an important role in the cellular processes of DNA repair resulting from either endogenous insults (such as reactive oxygen species or hydroxy radicals) or exogenous factors such as ionizing radiation (IR), both of which can generate highly cytotoxic double-strand breaks (DSBs) in the DNA that can undermine genomic integrity. A primary pathway of repairing DSBs is nonhomologous end-joining (NHEJ), which employs the products of DNA-dependent serine/threonine protein kinase (DNA-PK), XRCC6 (KU70), XRCC5 (KU80), LIG4, XRCC4 and Artemis, which was recently reported [19-21]. Numerous studies have focused on the association between these XRCC protein polymorphisms and their role in lung cancer [22,23]. The role of XRCC proteins has also been evaluated in hepatocellular carcinoma (HCC) [24] and breast cancer [25].

We propose to quantify XRCC4 in complex samples (i.e., bovine serum albumin (BSA), cells and tissue) by:

- Using stable isotope-labeled full-length protein XRCC4 (labeled $\left[\mathrm{U}_{-}{ }^{13} \mathrm{C}_{6},{ }^{15} \mathrm{~N}_{4}\right]$-L-arginine and $\left[\mathrm{U}_{-}{ }^{13} \mathrm{C}_{6},{ }^{15} \mathrm{~N}_{2}\right]$-L-lysine) as IS, to minimize the assay variation from digestion, sample extraction and LC-MS/MS analysis;
- Using the summed peak area from selected fragments of the target peptide via NanoLC and high-resolution MS/MS (0.05 Da for both parent and fragment ions) with TripleTOF, to enhance selectivity and sensitivity;

- Reporting relative quantification of XRCC proteins (XRCC1, XRCC5 and XRCC6) and DNA-PK in human matrixes by using heavy-labeled XRCC4 as IS.

Initially, a fit-for-purpose method qualification was conducted for quantifying XRCC4 with a surrogate matrix (BSA, which contains no endogenous XRCC4) resulting in the establishment of a selective, sensitive, linear and accurate method. Second, the qualified method for XRCC4 was applied to quantify XRCC4 in three cancer cell lines (HEK-293, HeLa and Ramos) and human cancer tissues (lung and lymphoma). Finally, we applied the method by using the stable-labeled XRCC4 as IS, to estimate the protein concentrations of XRCC1, XRCC5, XRCC6 and DNA-PK in the cancer cell lines and tissues without any pre-analytical immunoaffinity enrichment. The quantitative protein expression profiles of XRCC (XRCC1, XRCC4, XRCC5 and XRCC6) and DNA-PK in cancer cells (HEK-293, HeLa and Ramos) and tumor samples (lung and lymphoma) are reported.

\section{Experimental}

Materials \& reagents

The unlabeled and heavy isotope-labeled XRCC4 proteins were purchased from Origene (MD, USA). The recombinant XRCC4 protein was produced with TrueORF clone, RC212684, encoding the full-length human XRCC $4(0.23 \mu \mathrm{g} / \mu \mathrm{l})$ with C-terminal DDK tag, from human HEK293 cells. The heavy-labeled protein XRCC4 was universally labeled using $\left[\mathrm{U}_{-}{ }^{13} \mathrm{C}_{6},{ }^{15} \mathrm{~N}_{4}\right]$-L-arginine and $\left[\mathrm{U}_{-}{ }^{13} \mathrm{C}_{6},{ }^{15} \mathrm{~N}_{2}\right]$-L-lysine $(0.23 \mu \mathrm{g} / \mu \mathrm{l}$ for $\sim 10 \mu \mathrm{l}$ solution). Protein concentrations were determined via bicinchoninic acid assay (BCA). Origene reports the purity $>80 \%$ as determined by SDS-PAGE and Coomassie blue staining and the labeling efficiency $>90 \%$. The heavy-labeled protein was obtained as a $0.23 \mu \mathrm{g} / \mu \mathrm{l}$ solution and a working solution was created by diluting $4.35 \mu \mathrm{l}$ of stock heavy XRCC4 $(38,685 \mathrm{~g} / \mathrm{mol})$ in $995.65 \mu \mathrm{l}$ of water, and then using this working solution to spike $15.2 \mu \mathrm{l}$ into a sample before adjusting the final volume to $100 \mu \mathrm{l}$ for a final IS concentration of $9.047 \mathrm{nM}$. Dithiothreitol (DTT), iodoacetamide (IAM), trifluoroethanol (TFE) and ammonium bicarbonate (Ambic) were purchased from Sigma Aldrich (MO, USA). Formic acid (FA) was purchased from Thermo Fischer Scientific (PA, USA). Sequencing grade trypsin was purchased from 
Promega (Madison, WI). HEK-293, HeLa and Ramos cell lines were purchased from ATCC (VA, USA).

\section{Cell culture \& collection}

HeLa and HEK-293 cells were cultured in minimum essential media from Invitrogen (NY, USA) supplemented with $10 \%$ fetal bovine serum purchased from Invitrogen. Ramos cells were cultured in RPMI 1640 media also from Invitrogen supplemented with $10 \%$ fetal bovine serum. All cells were grown and maintained at $37^{\circ} \mathrm{C}$ in $5 \%$ carbon dioxide.

Cells were grown to approximately $75 \%$ confluency before harvesting. As the cells begin to form a monolayer in culture they start to experience contact inhibition-induced growth arrest. However, at 75\% confluency, not all cells are in contact with one another. For HeLa and HEK-293 cells $0.25 \%$ trypsin from Invitrogen was added to culture dishes and allowed to incubate for $10 \mathrm{~min}$ at $37^{\circ} \mathrm{C}$ to detach cells from plate. HeLa and HEK-293 cells were then scrape collected while Ramos cells (suspension) were collected and all cells were centrifuged at $500 \times \mathrm{g}$ at $4^{\circ} \mathrm{C}$. The supernatant was removed and the cell pellet was resuspended in magnesium and chloride free phosphate buffered saline (PBS) from Invitrogen and centrifuged again at $500 \times \mathrm{g}$ at $4^{\circ} \mathrm{C}$. Pelleted cells were resuspended in $1 \mathrm{ml}$ $1 \times$ PBS and an aliquot was taken for cell counting and the cells were spun down again before the pellet was frozen in liquid nitrogen and stored at $-80^{\circ} \mathrm{C}$. Cell suspension aliquots were counted using a Neubauer hemocytometer grid and (depending on the cell line) approximately $6-10 \times 10^{6}$ cells were calculated in $1 \mathrm{ml}$ of $1 \times$ PBS. Protein lysates were prepared as described in the following section. Briefly, cell pellets were resuspended in $200 \mu \mathrm{l}$ of 1:1 trifluoroethanol:100 mM ammonium bicarbonate lysis buffer bringing the cell concentrations to 30,000-50,000 cells/ $\mu$ l. Depending on the BCA assay values only a fraction of the lysate 6-10 $\mathrm{Hl}$ (or approximately 300,000 cells) was aliquoted for digestion. Tryptic peptide extracts were reconstituted in $100 \mu \mathrm{l}$ final volume of $2 \%$ acetonitrile $(\mathrm{ACN}) / 0.1 \% \mathrm{FA}$ of which $5 \mu \mathrm{l}(15,000$ cells $)$ were injected onto the C18 reverse phase column for MS analysis.

\section{Cell \& tissue preparation for MS analysis}

Ramos, HeLa and HEK-293 cell pellets were resuspended and lysed in $100 \mathrm{ul}$ of ammonium bicarbonate (100 mm, pH 8.0) mixed with 100 ul of TFE (1:1) and then incubated at $60^{\circ} \mathrm{C}$ for $60 \mathrm{~min}$ at $1000 \mathrm{rpm}$ on an Eppendorf thermomixer before sonicating at $30 \mathrm{~W}$ and $20 \%$ output for ten $1 \mathrm{~s}$ pulses. Protein concentration was assessed using BCA kit from Pierce (\#23227, IL, USA). $10 \mu \mathrm{g}$ aliquots of sample were prepared, spiked with heavy isotope-labeled IS $(9 \mathrm{fmol} / \mu \mathrm{l}$ final concentration) then subsequently reduced with $10 \mathrm{mM}$ DTT (final concentration) at $60^{\circ} \mathrm{C}$ for $30 \mathrm{~min}$ at $1000 \mathrm{rpm}$ on an Eppendorf thermomixer and then incubated at ambient temperature in the dark for $30 \mathrm{~min}$ with $20 \mathrm{mM}$ iodoacetamide (final concentration). The samples were diluted with $50 \mathrm{~mm}$ ammonium bicarbonate, $\mathrm{pH} 8.0$ (to 10\% TFE) before adding Trypsin at a 1:50 $(\mathrm{w} / \mathrm{w})$ ratio and incubating overnight at $37^{\circ} \mathrm{C}$ with shaking. The digestions were quenched with $0.1 \%$ TFA (v/v) and then evaporated to dryness in vacuo. The samples were resuspended in $100 \mu \mathrm{l}$ of $5 \%$ FA in water, vortex-mixed vigorously, and desalted with C18 Stage Tips (SP301) from Thermo Fisher Scientific (PA, USA). Briefly, Stage Tips were placed through a hole in the top of a $1.5 \mathrm{ml}$ Eppendorf tube (allowing enough room for flow through), loaded from the top and spun in a $4^{\circ} \mathrm{C}$ centrifuge at $1500 \times \mathrm{g}$ for $2-5 \mathrm{~min}$. Tips were first activated with $80 \%$ ACN in water with $5 \% \mathrm{FA}$, washed with 5\% FA in water, then loaded with sample. Tips were equilibrated with 5\% FA in water before loading sample in the top of tip and spinning in Eppendorf for $2 \mathrm{~min}$. Sample was passed through the tip twice to ensure maximum binding. Peptides were eluted with two washes of $80 \%$ ACN with $5 \%$ FA in water and evaporated in vacuo. Digests for MS analysis were reconstituted in $0.1 \%(\mathrm{v} / \mathrm{v})$ aqueous FA with $2 \%$ $\mathrm{ACN}$ to a final concentration of $100 \mathrm{ng} / \mu \mathrm{l}$.

Tumor samples were acquired as tissue flash-frozen and embedded in optimal cutting temperature (OCT) solution from Origene (MD, USA). Two sets of three $30 \mu \mathrm{m}$ slices were cut from each tumor block and placed into $1.5 \mathrm{ml}$ Eppendorf tube (three slices per tube, roughly $15-20 \mathrm{mg}$ wet weight). Excess OCT liquid was removed at room temperature using gel-loading pipette tip. Tumor samples for MS analysis were prepared and spiked with IS as described above for cultured cells, except that in the initial protein solubilization step, the tissue samples were sonicated three-times at $30 \mathrm{~W}$ and $20 \%$ output continuously for $20 \mathrm{~s}$ both before and after $60 \mathrm{~min}$ of incubation in $50 \mathrm{~mm}$ ammonium bicarbonate with $50 \%$ TFE on ice. Digested tissue samples were desalted using C18 Stage Tips as described above, evaporated in vacuo, and resuspended in $0.1 \%(\mathrm{v} / \mathrm{v})$ aqueous FA with $2 \% \mathrm{ACN}$ to a final concentration of $100 \mathrm{ng} / \mu \mathrm{l}$ for LC-MS/MS analysis.

\section{LC \& MS conditions}

LC-MS/MS analyses were performed on 5600 TripleTOF mass spectrometer from AB SCIEX (MA, USA) equipped with an Eksigent NanoLC 1D plus pump and Eksigent autosampler (CA, USA). Sample injections of $5 \mu \mathrm{l}$ were made (500 ng total protein on column) using 


\section{Key term}

Information-dependent acquisition: Type of MS acquisition including a survey scan (TOF-MS scan) and product ion (MS/MS scan). The survey scan scans the entire $\mathrm{m} / \mathrm{z}$ range, while parameters for the product ion scans are set to generate MS/MS for the top 25 ions detected in the survey scan. This results in the $>3000$ scan cyles performed during a single injection. These MS/MS spectra are then searched against a database to generate protein identifications.

a trap and elute method, where a $350 \mu \mathrm{m} \times 0.5 \mathrm{~mm}$ C18 trap column packed with $3 \mu \mathrm{m} 120$ A C18 resin. The peptides were resolved on a Chrom XP $0.075 \times 150 \mathrm{~mm}$ column from Eksigent (MA, USA) packed with $3 \mu \mathrm{m} 120$ A C18 resin. LC was carried out at ambient temperature over 80 min using a gradient mixture of $0.1 \%(\mathrm{v} / \mathrm{v}) \mathrm{FA}$ in water (solvent $\mathrm{A}$ ) and $0.1 \%(\mathrm{v} / \mathrm{v}) \mathrm{FA}$ in ACN (solvent B). A $7 \mathrm{~min}$ load period using $100 \%$ solvent $A$ at $3 \mu \mathrm{l} / \mathrm{min}$ was followed by an elution gradient ( $300 \mathrm{nl} / \mathrm{min}$ ) from 2 to $25 \%$ solvent B in $30 \mathrm{~min}, 25$ to $90 \%$ solvent B over $15 \mathrm{~min}$, and held at $90 \%$ solvent B for 17 min before returning to $5 \%$ solvent B to equilibrate column. Peptides eluting from the capillary tip were introduced into the 5600 via Nanospray source with a capillary voltage of approximately $2.4 \mathrm{kV}$.

\section{MS analyses}

Quantitative analyses were done using the stable isotope-labeled, full-length protein, XRCC4 $\left({ }^{13} \mathrm{C}_{6}\right.$, $\left.{ }^{15} \mathrm{~N}_{4}\right)$ for arginine and $\left({ }^{13} \mathrm{C}_{6},{ }^{15} \mathrm{~N}_{2}\right)$ for lysine as the IS. Signature peptides for each protein measured were required to be between seven and 25 amino acids long and were selected based on uniqueness to single protein and chemical stability. Although priority was given to peptides that were previously identified in shotgun experiments with high MS/MS spectral quality, additional peptides were selected by in silico digestion. Peptide uniqueness was confirmed by BLAST searching sequences against the UniProt database. At least four fragment ions were monitored for target peptides and the standard. MS data was imported into Skyline software, smoothed using a second derivative transformation and the software was used to extract and integrate transition peak areas for each target peptide. Retention times $(\leq 0.5 \mathrm{~min})$ and high resolution with accurate mass $(\leq 0.05 \mathrm{Da}) \mathrm{MS} / \mathrm{MS}$ spectra were used to confirm peak identifications. Sum peak areas for target peptide transitions were divided by the sum peak area for the IS peptide transitions to give peak area ratio (PAR) for standard and QC samples prepared in BSA. The concentrations of XRCC4 and the remaining XRCC family proteins as wells as DNA-PK were calculated by the following equation:

$$
\mathrm{A}(\mathrm{k})=\frac{\sum_{\mathrm{j}=1}^{\mathrm{n}}(\mathrm{i}[\mathrm{j}]) \times \mathrm{C}}{\left.\sum_{\mathrm{l}=1}^{\mathrm{nIS}}\left(\mathrm{IS}_{[} \mathrm{l}\right]\right)}
$$

where:

- A: protein concentration based on the peptide $\mathrm{k}$, in fmol of total protein with the matrix;

- $\quad \mathrm{i}$ : fragment ion peak area for peptide $\mathrm{k}$, in count per second (CPS);

- $\mathrm{j}$ : fragment ion for the peptide $\mathrm{k}$;

- 1 : fragment ions have been identified for the peptide from the heavy-labeled protein XRCC4, $\mathrm{n} \geq 4$;

- $n$ : maximum number of the fragment ions have been identified for the peptide $\mathrm{k}, \mathrm{n} \geq 4$;

- nIS: maximum number of the fragment ions have been identified for the peptide from the heavy-labeled protein, $\mathrm{n} \geq 4$;

- IS: peak area of the fragment ion for the peptide from the heavy-labeled protein XRCC4 (CPS);

- $\mathrm{C}$ : the concentration of the heavy-labeled protein XRCC4 (fmol) with the matrix.

Coefficients of variation (CVs) were calculated across replicates for each treatment. For MS analyses in cell culture experiments, three replicate cell cultures were analyzed for each cell culture and treatment, while MS analysis of tissue samples included two replicate sample preparations from the same tissue block.

\section{Database search for protein identification}

For the purchased light and heavy isotope-labeled XRCC4 proteins as well as processed cell and tissue lysate, information-dependent acquisition (IDA) methods using the same LC methods described previously were performed to identify and verify the proteins. Briefly, one full scan was performed followed by four MS/MS scans of the most abundant peaks. The acquired high-resolution MS/MS spectra were converted into mass lists using PeakView program from AB SCIEX and searched against the UniProt/SwissProt protein database containing human sequences using the ProteinPilot program (AB SCIEX). The searches were performed allowing for tryptic peptides only with peptide mass tolerance of $0.05 \mathrm{Da}$ and a minimum of four fragment ions in one MS/MS scan. The false-positive identification rates were $\leq 1 \%$. Proteins were identified based on at least two uniquely identified peptides. 


\section{Results}

There are two major challenges for an LC-MS/MS method to quantify proteins in human matrices:

- Insufficient sensitivity because of the low abundance of target proteins in a complex sample;

- Assay reproducibility resulting from uncontrolled analytical processes, such as, analyte (i.e., peptides) stability, accuracy and precision not established prior to sample analysis $[26,27]$.

In order to address these challenges, we:

- Applied NanoLC coupled with NanoSpray high-resolution MS/MS to improve the analyte selectivity and reduce the interference from highly abundant proteins;

- Spiked the stable-labeled full-length XRCC4 protein as an IS, which not only helps to account for digestion efficiency, but also to ensure assay accuracy and precision;

- Utilized the summed peak areas from all monitored fragment ions of the target peptide as the response to improve the $\mathrm{S} / \mathrm{N}$ ratio [28].
To minimize assay variation in our work flow, stable-labeled XRCC4 was spiked into samples prior to digestion and the total sample was processed and eluted into the mass spectrometer using the NanoLC column (500 ng total proteins for all the experiments). The optimized sample preparation work flow for cancer cells and tissues is shown in Supplementary Figure 1. The extracted ion chromatograms for the five peptides monitored from the XRCC4 protein can be seen in Figure 1. The accurate mass measurements $(\leq 0.05 \mathrm{Da})$ for precursor/fragment ions of the targeted peptides ensure the specificity of the analyte.

\section{Development of high-resolution multiple reaction monitoring for XRCC \& DNA-PK proteins}

Spectral libraries for the reference standard XRCC4 and isotope-labeled XRCC4 (as IS) were generated using NanoLC followed by IDA of MS/MS spectra using a Sciex TripleTOF 5600. Based on IDA data collected from the two forms of XRCC 4 and ProteinPilot database search, prominent peptides were selected. The protein coverage for isotope-labeled and nonlabeled XRCC4 was approximately 60\% (data not
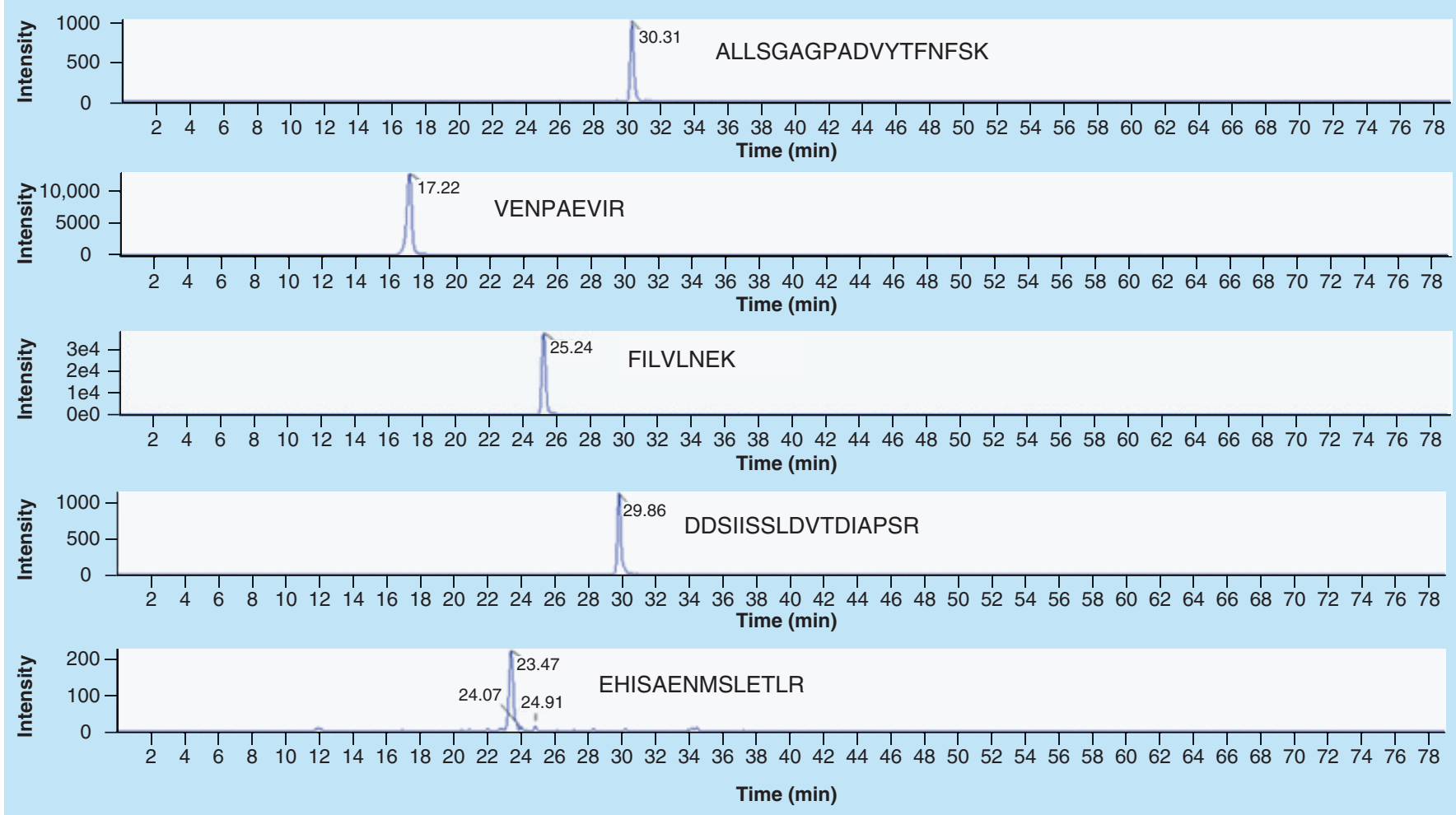

Figure 1. Extract ion chromatogram of digested peptides from XRCC4 protein in bovine serum albumin. Extracted ion chromatograms are shown for five peptides from XRCC4 ( $90 \mathrm{fmol}$ on column) spiked into $100 \mathrm{ng} / \mathrm{\mu l}$ of bovine serum albumin ( $500 \mathrm{ng}$ on column). Each extracted ion chromatogram represents one selected fragment ion from the targeted XRCC4 peptide precursor ion. 
shown). Over 1000 different proteins were observed in each cell and tissue type when an unfractionated injection was performed for shotgun analysis (data not shown). No XRCC4 was detected during these analyses, however, some peptide sequences used for quantification of XRCC5 and XRCC6 (HIEIFTDLSSR and NIYVLQELDNPGAK, respectively) as well as DNA-PK (VTELALTASDR) were selected from the IDA data and supplemented with additional high-ranking recommendations from Skyline (University of Washington, WA, USA). Targeted MS/MS analysis for XRCC and DNA-PK proteins was performed by producing high resolution full MS/MS spectrum for each peptide in the transition list (Table 1). At least four fragment ions (transitions) were selected per peptide using the most intense $y$-ions/b-ions typically with $\mathrm{m} / \mathrm{z}$ greater than the precursor $\mathrm{m} / \mathrm{z}$. MS/MS spectra of all the unique heavy peptides identified in these 18 peptide candidates were manually inspected (Table 1 \& Figure 2), the unique heavy peptide was chosen, and the transition from the precursor ion to the most intense fragment ion for each of these five heavy peptides was identified, thus generating a set of five heavy multiple reaction monitoring-high resolution transitions. On the basis of this list of transitions, IS transition list was generated using the calculated mass of each peptide assuming labeling of all arginine $\left(\mathrm{R},{ }^{13} \mathrm{C}_{6},{ }^{15} \mathrm{~N}_{4}\right)$ and lysine $\left(\mathrm{K},{ }^{13} \mathrm{C}_{6},{ }^{15} \mathrm{~N}_{2}\right)$ residues (Supplementary Figure 2).

\section{Purity of stable isotope-labeled XRCC4} reference standards

The isotopic purity of the stable labeledXRCC4 was evaluated; the results can be seen in Supplementary Table 1. In brief, the isotopic purity evaluation was conducted by measuring both labeled peptide (i.e., arginine $\left[R,{ }^{13} \mathrm{C}_{6}\right.$, $\left.{ }^{15} \mathrm{~N}_{4}\right]$ and lysine $\left[\mathrm{K},{ }^{13} \mathrm{C}_{6},{ }^{15} \mathrm{~N}_{2}\right]$ ) and unlabeled peptide (arginine $\left[\mathrm{R},{ }^{12} \mathrm{C}_{6},{ }^{14} \mathrm{~N}_{4}\right]$ and lysine $\left[\mathrm{K},{ }^{12} \mathrm{C}_{6},{ }^{14} \mathrm{~N}_{2}\right]$ ) signals in a neat solution digest of only labeled XRCC4 protein. Peak area signal detected for unlabeled peptide was divided by total peak area detection (unlabeled signal + labeled signal) and multiplied by 100 to calculate percentage impurity. Although, certificate of analysis indicated approximately $90 \%$ labeling efficiency, the

Table 1. LC-MS/MS quantification assay summary for determination XRCC and DNA-protein kinase proteins in human matrix.

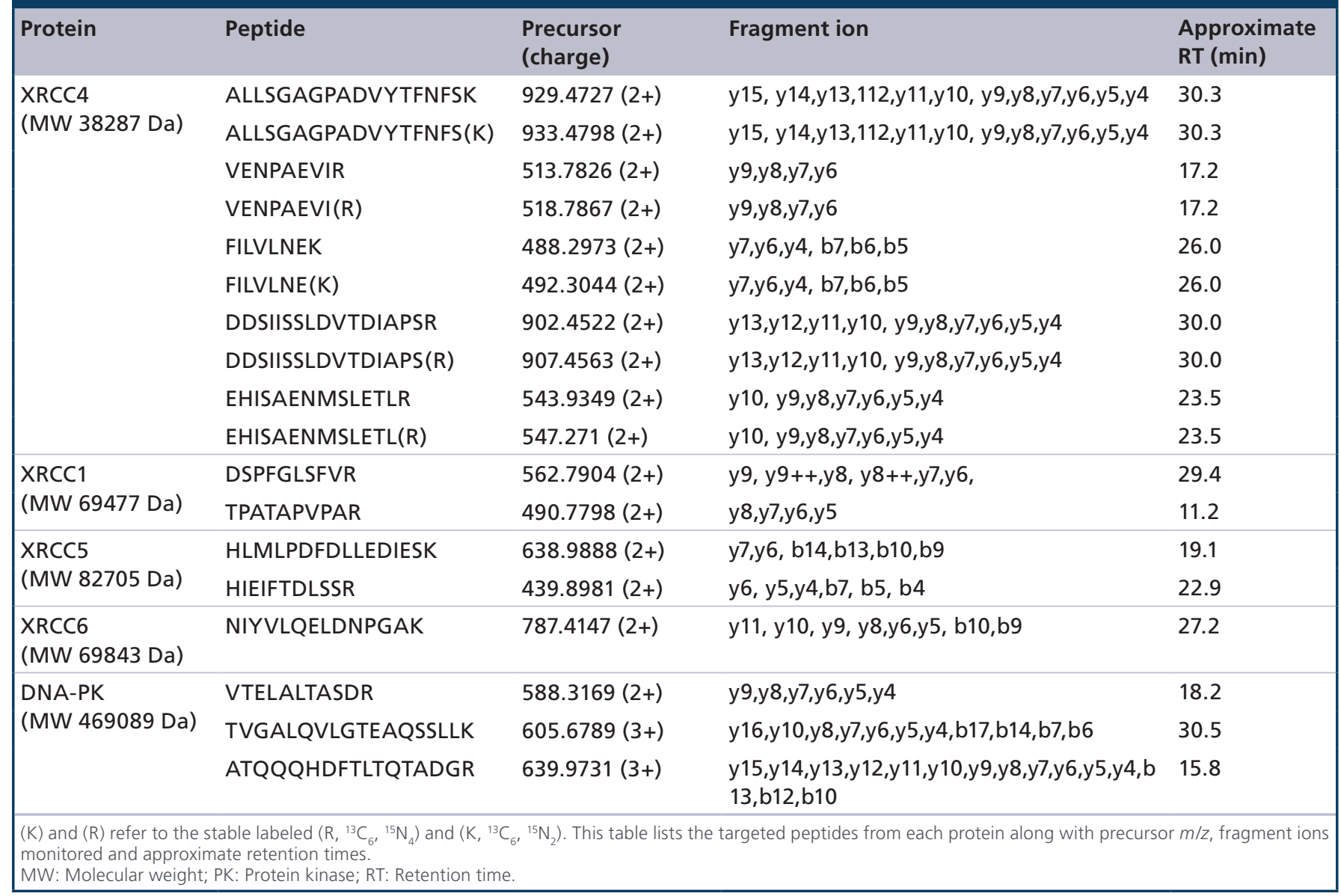




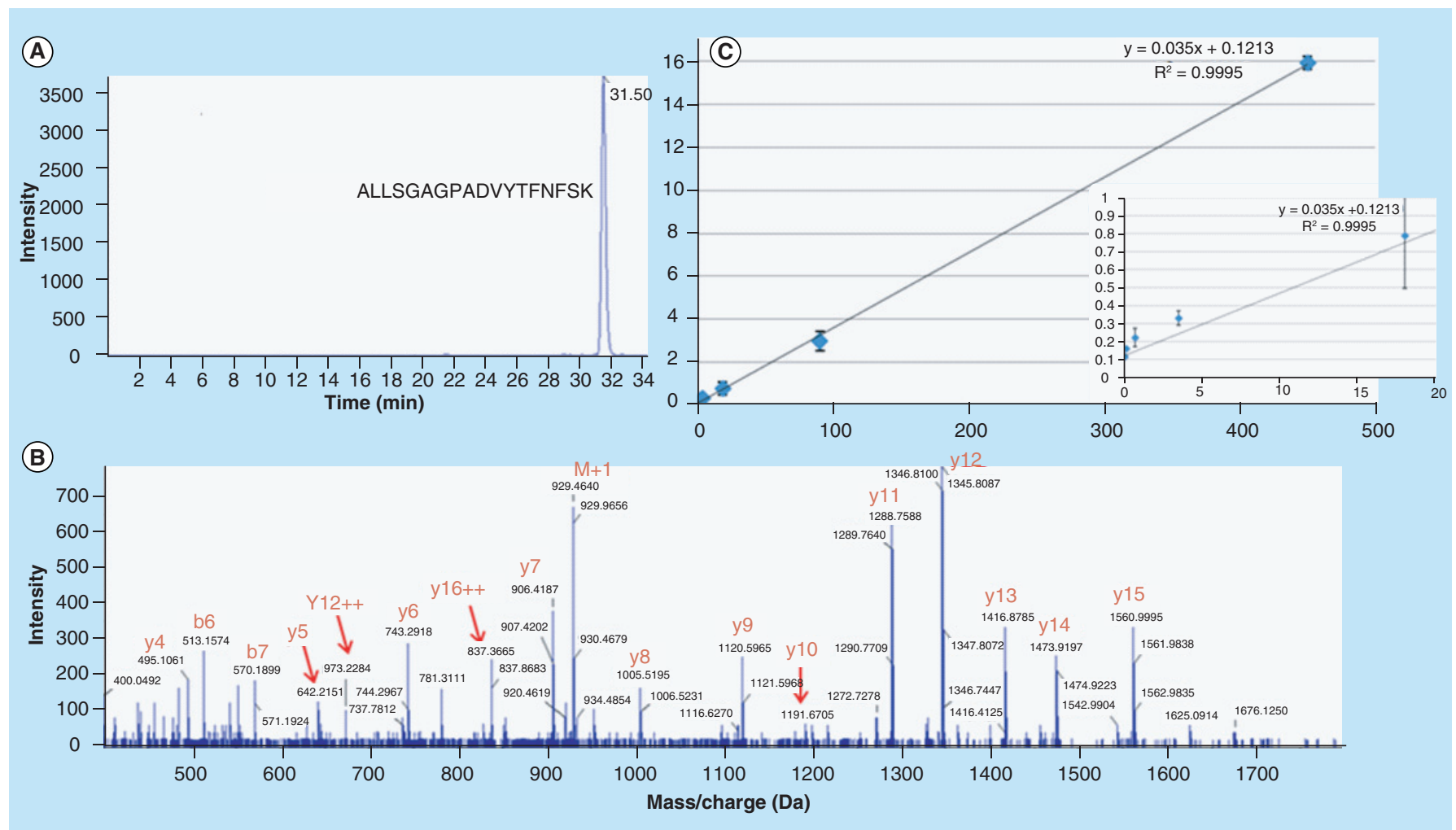

Figure 2. MS/MS spectra of XRCC4 peptide ALLSGAGPADVYTFNFSK $(929.4727,2+)$ from QC in bovine serum albumin.

(A) Chromatogram and (B) MS/MS of the ALLSGAGPADVYTFNFSK peptide from light XRCC4 (90 fmol on column) spiked into bovine serum albumin $500 \mathrm{ng}$ on column. (C) Standard curve for digested XRCC4 peptide ALLSGAGPADVYTFNFSK; displays the curve and $\mathrm{r} 2$ value for the ALLSGAGPADVYTFNFSK peptide spiked into bovine serum albumin. The curve is comprised of seven points where heavy-labeled XRCC4 is spiked in at a constant concentration of $9 \mathrm{fmol} / \mu \mathrm{l}$ with increasing concentration spikes of light XRCC4. The smaller insert displays the lower curve with five lower standards $(0.028,0.14,0.7,3.5$ and $18 \mathrm{fmol})$.

isotopic purity was determined to range from $86-89 \%$. It is important to note that there is approximately a $12 \%$ signal contribution from the stable-labeled XRCC4 to the quantification of unlabeled XRCC4 highlighting the importance of verifying standard purity. This impurity was taken into account when calculating XRCC4 concentration values by multiplying the percentage purity for each peptide (Supplementary Table 1) by the values calculated in standards and QCs, as well as human cancer cell lines and tissues.

\section{Stability of XRCC4 in processed samples}

The stability evaluation of the digested peptides in the processed samples (BSA matrix) is shown in Supplementary Table 2. The \%CV across all peptides and time points ranged from 0.7 to $35 \%$ with an average of $11.1 \%$. The processed sample for the DDSIISSLDVTDIAPSR peptide is relatively stable in BSA for about $48 \mathrm{~h}$ at approximately $4^{\circ} \mathrm{C}$ displaying the lowest \%difference values $(<10 \%)$. While the other monitored peptides did not all display similar stability under the same conditions (\% difference ranging from 35-64\%) between time points, the stable labeled XRCC4 was able to make corrections for the loss of material for the ALLSGAGPADVYTFNSFK and VENPAEVIR peptides (Supplementary Table 2) bringing the percentage difference between time points for both peptides to under $20 \%$.

\section{Development of quantification assay for XRCC4 proteins}

The quantitative analysis of XRCC4 protein in BSA was evaluated with five peptides resulting from trypsin digestion of XRCC4. The concentration response curve (i.e., standard curve) was generated by analyzing each concentration point on 5600 TripleTOF. The protein concentration was calculated based on the equation in the section titled 'Experimental', the concentration of the heavy-labeled protein XRCC4 (fmol) multiply the PAR, which is sum of transition peak areas for the analyte peptide divided by the sum of transition peak areas for the corresponding stable isotope-labeled peptide. There are at least four fragment ions extracted from the

\section{Key term}

Stability evaluation: Stability testing will evaluate the stability of the analytes during sample collection, storage (i.e., $-20^{\circ} \mathrm{C}$ ) and analytical process. 
full MS/MS spectrum for each peptide. The PAR of the peptide is generated by dividing the summed peak area of peptide fragment ions by summed peak areas from the stable isotope-labeled fragment ions.

The standard curves have seven points ranging from 0.028 to $450 \mathrm{fmol} / 500 \mathrm{ng}$ protein of XRCC4 in BSA and were generated by analyzing each standard in replicate $(\mathrm{n}=4)$, with two biological replicates and two analytical replicates (Figure 2C, insert). The heavy isotope-labeled XRCC4 protein was spiked in the standards, QCs and samples before digestion to a final concentration of $9 \mathrm{fmol} / \mu \mathrm{l}$. In this case, the intra- and inter-day, accuracy and precision of QCs were established for the standard in BSA. For each XRCC4 peptide monitored for the standard curve, extracted ion chromatograms (XICs) for at least four fragment ions from each peptide were chosen (Table 1) based on the accurate mass for both precursor and daughter ions (within $0.05 \mathrm{Da}$ ).

The slopes of standard curves for the five digested peptides from XRCC 4 and correlation coefficients $\left(r^{2}\right)$ for all the peptides are presented in Supplementary Table 3.
Although, the peptides have different chemical properties (i.e., sequence, solubility), the $r^{2}$ values are $>0.99$ for all peptides.

The CV and RE for all back-calculated standard values for the five peptides of XRCC4 are presented in Table 2. In general, the intra-day precision $(\% \mathrm{CV})$ of the second run (i.e., digestion, extraction and LC-MS analysis) was much better than the first run. The best intra- and inter-day precision was within $25 \% \mathrm{CV}$ for peptide ALLSGAGPADVYTFNFSK across all seven standards. In contrast, for the FILVLNEK peptide, the $\mathrm{CV}$ ranges up to $67 \%$ with a higher average across inter- and intra-day samples than any other targeted peptide ( 38\%).

The RE for three of the five peptides (ALLSGAGPADVYTFNFSK, VENPAEVIR and EHISAENMSLETLR) was significantly high for the lowest curve point (0.028 fmol on column) and in some cases (VENPAEVIR, DDSIISSLDVTDIAPSR and EHISAENMSLETLR) the second lowest curve point (0.140 fmol on column) indicating interference from an inability to distinguish target signals from basal

\begin{tabular}{|c|c|c|c|c|c|c|c|c|}
\hline XRCC4 peptides & Fmol/500 ng total protein & 0.028 & 0.14 & 0.7 & 3.5 & 18 & 90 & 450 \\
\hline \multirow[t]{4}{*}{ ALLSGAGPADVYTFNFSK } & Run 1 (\%CV) & 0.13 & 4.64 & 14.29 & 3.53 & 14.01 & 12.81 & 4.01 \\
\hline & Run $2(\% \mathrm{CV})$ & 11.07 & 13.62 & 18.08 & 25.02 & 7.07 & 16.98 & 1.60 \\
\hline & Average back-calculation & 0.096 & 0.184 & 0.48 & 2.99 & 19.68 & 87.79 & 450.39 \\
\hline & $\operatorname{RE}(\%)$ & 241.97 & 31.27 & 30.93 & 14.63 & 9.35 & 2.46 & 0.09 \\
\hline \multirow[t]{4}{*}{ VENPAEVIR } & Run $1(\% \mathrm{CV})$ & 32.66 & 12.85 & 4.81 & 23.44 & 42.15 & 6.38 & 5.11 \\
\hline & Run $2(\% \mathrm{CV})$ & 26.86 & 4.89 & 3.32 & 8.71 & 14.78 & 8.33 & 7.99 \\
\hline & Average back-calculation & 0.540 & 0.369 & 0.56 & 1.77 & 16.05 & 87.64 & 475.11 \\
\hline & $\operatorname{RE}(\%)$ & 1828.80 & 163.65 & 20.23 & 49.55 & 10.83 & 2.62 & 5.58 \\
\hline \multirow[t]{4}{*}{ FILVLNEK } & Run $1(\% \mathrm{CV})$ & 56.17 & 34.24 & 58.63 & 67.23 & 39.67 & 2.74 & 10.37 \\
\hline & Run $2(\% \mathrm{CV})$ & 42.63 & 37.70 & 23.57 & 10.51 & 2.82 & 11.09 & 1.36 \\
\hline & Average back-calculation & 0.018 & 0.151 & 0.88 & 0.94 & 12.52 & 82.91 & 483.77 \\
\hline & RE (\%) & 35.86 & 8.21 & 26.05 & 73.27 & 30.45 & 7.88 & 7.50 \\
\hline \multirow[t]{4}{*}{ DDSIISSLDVTDIAPSR } & Run $1(\% \mathrm{CV})$ & 10.10 & 5.55 & 37.91 & 14.06 & 40.29 & 12.43 & 8.23 \\
\hline & Run $2(\% \mathrm{CV})$ & 35.28 & 33.57 & 9.75 & 36.68 & 31.41 & 3.91 & 5.45 \\
\hline & Average back-calculation & 0.022 & 0.920 & 0.23 & 2.48 & 15.71 & 114.80 & 407.85 \\
\hline & RE (\%) & 19.74 & 557.09 & 66.83 & 29.07 & 12.71 & 27.56 & 9.37 \\
\hline \multirow[t]{4}{*}{ EHISAENMSLETLR } & Run $1(\% \mathrm{CV})$ & 66.43 & 73.31 & 29.57 & 3.08 & 33.55 & 14.69 & 9.22 \\
\hline & Run 2 (\%CV) & 2.79 & 17.50 & 21.28 & 2.38 & 1.26 & 6.30 & 0.13 \\
\hline & Average back-calculation & 1.953 & 1.848 & 2.96 & 0.33 & 23.32 & 89.15 & 449.92 \\
\hline & $\operatorname{RE}(\%)$ & 6874.37 & 1220.14 & 323.16 & 90.46 & 29.56 & 0.94 & 0.02 \\
\hline
\end{tabular}


level noise signals. The relatively high level of intra-day (Table 2) as well as RE (\%RE, Supplementary Table 4) variation observed for the FILVLNEK peptide may be caused by signal interference as a result of monitoring only 4 pairs of short, peptide fragment ion transitions. Furthermore, when a closer look is taken at individual fragment ion peak areas for the FILVNEK peptide the data shows a great deal of variation for the $\mathrm{b} 5$ and $\mathrm{b} 6$ fragments detected especially at lower concentrations (0.028-0.700 fmol on column, data not shown). However, for the other three peptides (ALLSGAGPADVYTFNFSK, VENPAEVIR and DDSIISSLDVTDIAPSR) in the QC samples (Supplementary Table 4) the majority of \% RE and \%CV values are within the range of $1.5-30 \%$.

Since the MS signal of peptides identifying each protein can be used to estimate its absolute cellular abundance [29], the peak areas of known amount of IS (the stable isotope-labeled XRCC4) was used to calculate each peptide concentration in the QC samples in BSA. In this way, the accuracy and precision of the QC can be referenced for quantification of cell and tissue samples. Precision and accuracy of the method for the four peptides were determined by analyzing QC samples at three different protein concentrations (0.7, 18 and $90 \mathrm{fmol} / 500 \mathrm{ng}$ protein in BSA) within the standard curve range to evaluate reproducibility. Precision (\%CV) and accuracy (\%RE) were used to assess the assay performance during study sample analysis. The results for the quality control samples are presented in Supplementary Table 4. The \%CV for each QC level used in this study range was less than 24\% for ALLSGAGPADVYTFNFSK and DDSIISSLDVTDIAPSR. However, \%CV for each QC level was less than $49 \%$ for two shorter peptides of FILVLNEK and VENPAEVIR.

\section{Cancer cell analysis}

The well-characterized HEK-293, HeLa and Ramos cancer cell lines were evaluated for XRCC and DNA-PK proteins levels. While we did not assess the percentage of cells in each stage of the cell cycle, the cells were not synchronized to ensure a diverse population of cells as would be present in tissue samples. The full-length XRCC 4 heavy protein was spiked into the cell samples after the cell lysis and before digestion. Since the assay sensitivity, linearity and reproducibility for the five peptides of XRCC 4 (Supplementary Tables 3 \& 4) has been established in the BSA, we are able to quantitatively measure the digested peptides derived from XRCC4 in cell lysate based on the PARs of the peptides and corresponding stable labeled peptides. Table 3 shows the concentrations for the three peptides of XRCC 4 from three biological replicates of digested cell lysate.
The precision $(\% \mathrm{CV}, \mathrm{n}=3)$ is less than $17.2 \%$ for all of the XRCC4 peptides listed in the table across all three cell lines. The peptide concentrations for XRCC4 range from 9.34 to $18.45 \mathrm{fmol} / 500 \mathrm{ng}$ total proteins for HEK-293 cells, 5.09 to $11.40 \mathrm{fmol} / 500 \mathrm{ng}$ total protein for HeLa cells and 8.95 to $15.83 \mathrm{fmol} / 500 \mathrm{ng}$ total protein for Ramos cell lysate. The difference of the peptide concentrations from XRCC4 may due to the peptide stability (i.e., Supplementary Table 2). Therefore, the final reported concentrations of XRCC4 in HEK-293, HeLa and Ramos cell lines will be in the range 7-12 fmol/500 ng protein based on the ALLSGAGPADVYTFNFSK peptide concentration in the cell. A representative chromatogram with MS/MS fragmentation for the endogenous ALLSGAGPADVYTFNFSK peptide detected in HEK-293 cells in can be seen in Figure 3. The lack of detection of the DDSIISSLDVTDIAPSR and EHISAENMSLETLR peptides in the cell or tumor samples could be due to signal suppression by co-eluting species in a complex matrix or perhaps the possibility of post-translational modifications. There is potential for the oxidation of the methionine residue in the EHISAENMSLETLR peptide as well as the presence of multiple sites of possible phosphorylation in both of these peptides could complicate detection of these peptides $[19,20]$. No signal was detected when the samples were analyzed targeting the oxidized form $(+15.99 \mathrm{Da})$ of the EHISAENMSLETLR as well as fragments demonstrating neutral loss $(-64 \mathrm{Da})$ of $\mathrm{CH}_{3} \mathrm{SOH}$ (data not shown). Additional studies are required to address the phosphorylation state of these peptides.

The relative quantification for XRCC1, XRCC5, XRCC6 and DNA-PK in HEK-293, HeLa and Ramos cancer cell lines was also conducted based on the known amount of the stable labeled XRCC4 spiked into the cell lysate before the digestion and is shown for each target peptide in Table 3. Approximate concentrations for the proteins other than XRCC 4 were calculated based on the sum peak areas detected for the ALLSGAGPADVYTFNFSK peptide from the heavy-labeled XRCC4 (IS). The details of concentration calculations are described in the 'MS analyses' of the 'Experimental' section. The final reported concentrations of XRCC1, XRCC 5 and DNA-PK will be in the ranges of 12-20, $26-80,17-33$ and $68-80 \mathrm{fmol} / 500 \mathrm{ng}$ protein based on the peptides of DSPFGLSFVR-XRCC1, HLMLPDFDLLEDIESK-XRCC5 and VTELALTASDR-DNA-PK, respectively. The selected peptides for XRCC1, XRCC5 and DNA-PK were based on the analytical considerations (i.e., number of the fragments, charge state and \%CV). Although, the concentrations of XRCCs and DNA-PK are different by more than fourfold depending on the peptides (i.e., XRCC1 in Ramos, 
Table 3. XRCC and DNA-protein kinase protein concentration in human cancer cells ${ }^{\dagger}$.

\begin{tabular}{|c|c|c|c|c|}
\hline \multirow[t]{2}{*}{ Protein } & \multirow[t]{2}{*}{ Peptide } & \multicolumn{3}{|c|}{ Concentration ( $\mathrm{fmol} / 500 \mathrm{ng}$ total protein) $/ \% \mathrm{CV}(\mathrm{n}=3)$} \\
\hline & & Ramos & HEK-293 & Hela \\
\hline \multirow[t]{3}{*}{ XRCC4 } & ALLSGAGPADVYTFNFSK & $10.70 / 13.4$ & $11.63 / 15.9$ & $6.97 / 17.2$ \\
\hline & VENPAEVIR & $15.83 / 9.1$ & $18.45 / 1.2$ & $11.40 / 14.7$ \\
\hline & FILVLNEK & $8.95 / 12.7$ & $9.34 / 6.1$ & $5.09 / 9.9$ \\
\hline \multirow[t]{2}{*}{ XRCC1 } & DSPFGLSFVR & $12.01 / 7.3$ & $16.21 / 9.8$ & $20.80 / 6.3$ \\
\hline & TPATAPVPAR & $2.79 / 19.0$ & $6.26 / 19.4$ & $7.30 / 14.6$ \\
\hline \multirow[t]{2}{*}{$\mathrm{XRCC5}$} & HLMLPDFDLLEDIESK & $26.48 / 16.3$ & $55.16 / 6.6$ & $80.85 / 7.6$ \\
\hline & HIEIFTDLSSR & $8.59 / 9.4$ & $19.64 / 4.4$ & $22.41 / 4.0$ \\
\hline XRCC6 & NIYVLQELDNPGAK & $17.27 / 8.2$ & $30.51 / 6.0$ & $33.07 / 5.1$ \\
\hline \multirow[t]{3}{*}{ DNA-PK } & VTELALTASDR & $80.81 / 22.7$ & $68.88 / 18.3$ & $78.72 / 15.1$ \\
\hline & TVGALQVLGTEAQSSLLK & $40.23 / 18.7$ & $39.26 / 17.8$ & $36.40 / 13.6$ \\
\hline & ATQQQHDFTLTQTADGR & $15.63 / 13.5$ & $24.62 / 14.2$ & $20.63 / 10.2$ \\
\hline
\end{tabular}

Table 3), the concentration trends agreed with different peptides (i.e., XRCC1: HeLa > HEK-293 > Ramos; Table 3). Due to different charge states between the peptides and IS, the above trend does not apply to peptides in DNA-PK (TVGALQVLGTEAQSSLLK and ATQQQHDFTLTQTADGR) and IS (ALLSGAG-
PADVYTFNFSK-XRCC4). The high resolution MS/ MS spectra of digested peptides from XRCC1, XRCC5, XRCC6 and DNA-PK in HEK-293 cells are shown in Supplementary Figures 3-6, respectively. No signal was detected for the oxidized form or neutral-loss fragments for the HLMLPDFDLLEDIESK peptide
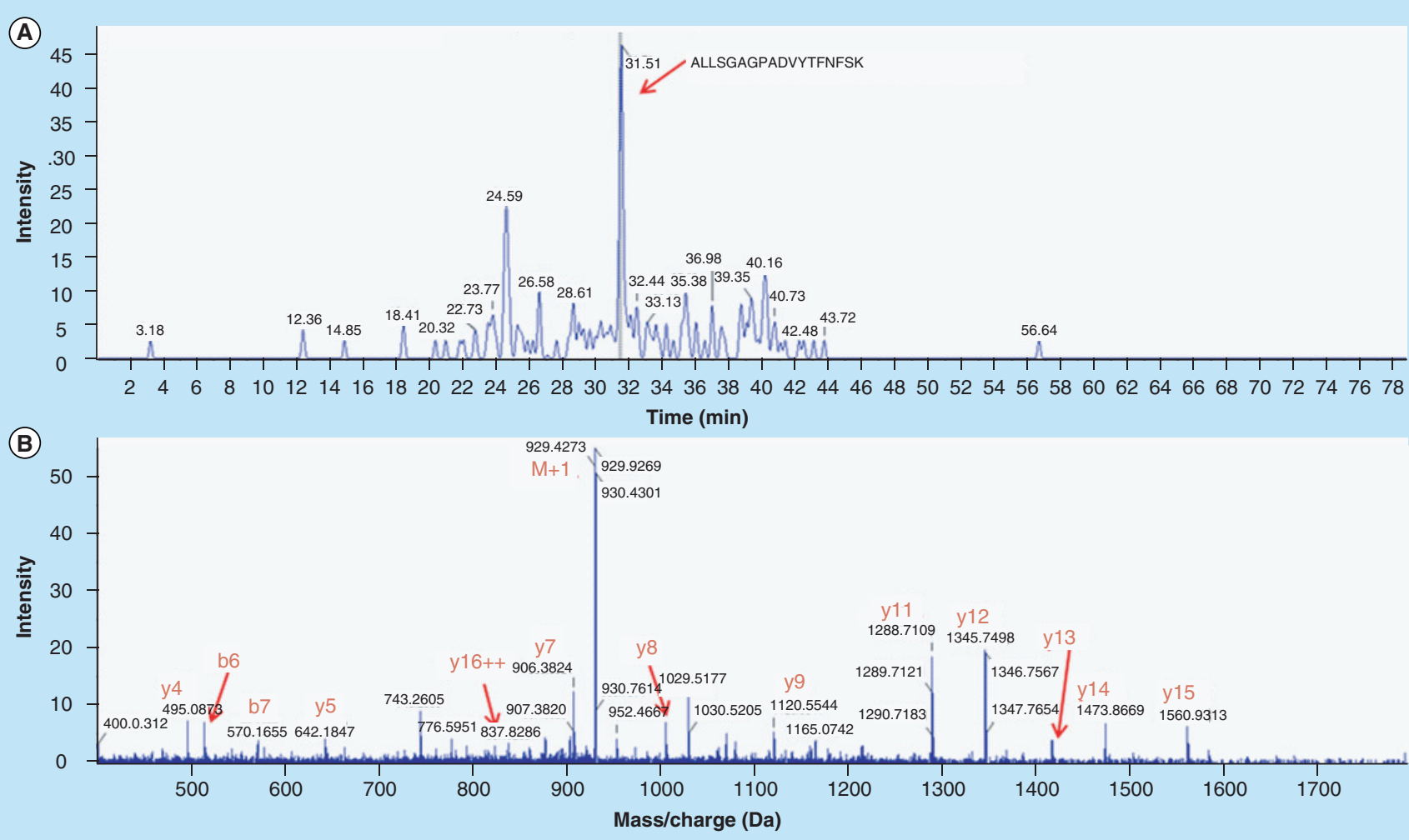

Figure 3. MS/MS spectra of XRCC4 peptide ALLSGAGPADVYTFNFSK $(929.4727,2+)$ from HEK-293 cell line. (A) Chromatogram and (B) MS/MS of the ALLSGAGPADVYTFNFSK peptide from the XRCC4 protein detected in HEK-293 cells (500 ng total proteins on column). 
of XRCC5 consistent with observations for the EHISAENMSLETLR methionine containing peptide from XRCC4. Although detection of additional XRCC and DNA-PK proteins can be confirmed by MS analysis, further evaluation is required to validate concentration levels.

\section{Protein copy number determination in cancer cells}

The absolute values for protein amounts ( $\mathrm{fmol}$ ) in the HeLa, Ramos or 293 cell lysates were used to calculate the corresponding copy numbers in each cell type. The highest protein expression level in this group of proteins (XRCC1, XRCC4, XRCC5, XRCC6 and DNA-PK) is DNA-PK in Ramos cells at approximately $80.81 \mathrm{fmol}$ (based on the peptide of VTELALTASDR concentration) across these cancer cell lines. Relatively, the XRCC4 protein is expressed at much lower levels, approximately $5.85 \mathrm{fmol}$ (based on the peptide of FILVLNEK concentration) in HeLa cells. When we converted the absolute protein amount (fmol) to the protein copy numbers per HeLa cell, there are approximately $3.13 \times 10^{6}$ copies of DNA-PK per HeLa cell, and approximately $2.34 \times 10^{5}$ copies of XRCC4 per HeLa cell, these values are in the range of the previous publications [30,31]. It is important to note that not all of the peptides detected and quantified in the XRCC4 standard curve were detected in the cell or tissue samples. This could be a result of increasing complexity or potential post-translational modifications that occur in the particular biological system.

\section{Tumor sample analysis}

The expression levels of DNA-PK, XRCC1, XRCC4, XRCC5 and XRCC6 proteins were investigated in lymphoma and lung tumor samples (Table 4). In the former, expression levels of XRCC 4 from two lymphoma samples were in the range of 2.85-8.49 fmol/500 ng protein on column. The protein levels were consistent, and the precision was $<6.3 \% \mathrm{CV}$ across the replicates ( $\mathrm{n}=4$, two biological replicates and two analytical replicates) when normalized (using the equation presented in the section titled 'Experimental') to the heavy-labeled XRCC4 peptide ALLSGAGPADVYTFNFSK. Protein expression levels detected for DNA-PK, XRCC4, XRCC5 and XRCC6 from a lung tumor sample ranged from 2.35 to $11.80 \mathrm{fmol} / 500 \mathrm{ng}$ protein. Of the three tumor samples analyzed, XRCC1 was only observed in one lymphoma sample (Table 4). No signal was detected for peptides TPATAPVPAR, HLMLPDFDLLEDIESK, TVGALQVLGTEAQSSLLK, or ATQQQHDFTLTQTADGR when targeted in the tissue samples.

\section{Discussion \& conclusion}

A general method of NanoLC HRMS using a stable labeled full-length protein as IS, and using the sum peak area of the transitions of the target peptide as the response was developed for quantifying target proteins in human cancer cell lines and tumor samples. In addition, the method was qualified as fit-for-purpose in analyte purity, stability, specificity, sensitivity, linearity, accuracy and precision, prior to sample analysis. We showed that the full-length XRCC4 used as a standard along with stable labeled XRCC4 (IS) was important for protein quantification by LC-MS/MS to track the multiple analytical steps, such as, digestion, extraction and LC-MS/MS. Lee et al. also showed the whole monoclonal antibody with stable labeled full-length monoclonal antibody had dramatically improved assay precision $[32,33]$. We established the accuracy and precision for XRCC4 along with stable labeled XRCC4 in BSA, and then proceeded to analyze peptides from additional XRCC family proteins and DNA-PK in three well-characterized cancer cell lines, HEK-293, HeLa and Ramos. Finally, we applied the method to

Table 4. XRCC and DNA-protein kinase proteins in human cancer tissues ${ }^{\dagger}$.

\begin{tabular}{|c|c|c|c|c|}
\hline \multirow[t]{2}{*}{ Protein } & \multirow[t]{2}{*}{ Peptide } & \multicolumn{3}{|c|}{ Concentration (fmol/500 ng total protein)/\% CV $(n=4)$} \\
\hline & & Lung cancer & Lymphoma-1 & Lymphoma-2 \\
\hline \multirow[t]{3}{*}{ XRCC4 } & ALLSGAGPADVYTFNFSK & $4.97 / 21.8$ & $4.14 / 6.3$ & $4.15 / 5.6$ \\
\hline & VENPAEVIR & $8.46 / 16.6$ & $4.86 / 67.5$ & $7.79 / 8.7$ \\
\hline & FILVLNEK & $4.84 / 23.7$ & $2.86 / 12.7$ & $4.47 / 13.2$ \\
\hline XRCC1 & DSPFGLSFVR & - & $8.01 / 5.0$ & - \\
\hline XRCC5 & HIEIFTDLSSR & $2.35 / 4.9$ & $8.16 / 1.6$ & $2.65 / 2.7$ \\
\hline XRCC6 & NIYVLQELDNPGAK & $8.92 / 6.4$ & $22.00 / 11.8$ & $13.01 / 2.3$ \\
\hline DNA-PK & VTELALTASDR & $11.80 / 11.6$ & $16.09 / 1.1$ & $7.75 / 7.4$ \\
\hline
\end{tabular}


analyze the target XRCC $(1,4,5$ and 6$)$ and DNA-PK proteins in human lymphoma and lung cancer tissues. It is noteworthy that although the precision $(\% \mathrm{CV})$ of the two short peptides (VENPAEVIR and FILVLNEK) in QC samples with BSA ranged up to 47.5 and 48.7\% (Supplementary Table 3); respectively, the precision in cancer cells was 14.7 and $12.7 \%$ for the same peptides (Table 3). This is an indication that interference for the short peptides may have originated from the BSA matrix.

Assessing the assay using the fit-for-purpose method qualification is an integral part of accurately quantifying the target proteins of interest. This is evidenced by the observation of an approximate signal contribution of $12 \%$, from the heavy XRCC 4 IS to the detection of the light XRCC4 peptide signals (Supplementary Table 1).

Since the analytical sample analysis run time is approximately $15 \mathrm{~h}$ for our NanoLC-high resolution MS analysis (i.e., mass calibration samples, QCs and samples), we established the approximate $48 \mathrm{~h}$ stability for process the samples at $4^{\circ} \mathrm{C}$ (Supplementary Table 2). Although, the current stability assessment for XRCC4 in BSA is based on the PAR of fragment ions and the IS from the peptides of XRCC4, the peptide stability for multiple target proteins can be evaluated if the IS is not available. In this case, the stability trends of the targeted proteins may be assessed with additional re-injections (i.e., 0, 4, 8, 12 and $24 \mathrm{~h}$ at $4^{\circ} \mathrm{C}$ ). Without proper qualification of analytical methods (especially the purity, the stability, the precision and the accuracy) protein expression detected in cells might not accurately represent the level of protein present in biological samples. This can result in misleading observations regarding the role of proteins in biological systems and their contribution to signaling networks and pathways. Although, the method has not been validated according to US FDA Guidance for bioanalytical method validation [34], the analyte purity, stability, accuracy and precision were evaluated in different matrixes, such as, BSA, cancer cell and tissues, respectively. The evaluation results provide a guidance for quantifying multiple proteins in different matrices.

Concentration data for XRCC4 peptides detected in cell and tissue were in an acceptable range across multiple peptides for each sample type (i.e., HeLa, Ramos, lymphoma, among others.). The ALLSGAGPADVYTFNFSK peptide from the heavy-labeled XRCC4 was chosen as the IS, for calculating the concentration of XRCC1, 5, 6, and DNA-PK across all biological samples (described in detail in the 'MS analyses' section). This peptide was selected due to its relatively low $\% C V s$ ( $<15 \%$ for standard curve and QCs), lack of known modifications to any residue in the peptide sequence and the fact that it was observed in all samples analyzed. The concentration data for XRCC1, XRCC5, and DNA-PK shows some disparity for the different peptides targeted in the human cell lines (Table 3). An interesting point to make is that concentrations calculated for XRCC5, XRCC6 and DNA-PK in cell and tissue samples was on average higher than those calculated for XRCC4 mirroring the observation that the three former proteins were detected in IDA (untargeted) MS scans while the lower abundant XRCC 4 was not detected. Although additional work is necessary to assess the stability of the peptides targeted when no labeled IS present/available, the varying concentrations determined for different peptides of the same protein highlights the need to target (when possible) multiple peptides per protein and further validate peptide targets to achieve an accurate measure of protein concentration in the biological samples as not all peptides display the same level of sensitivity.

Neither of the peptides containing the methionine residues (EHISAENMSLETLR-XRCC4 and HLMLPDFDLLEDIESK-XRCC5) were detected in oxidized forms or with neutral-loss fragments owing most likely to the sample preparation including reduction with DTT for $30 \mathrm{~min}$ at $60^{\circ} \mathrm{C}$. Moreover, the fact that neither of these peptides along with the DDSIISSLDVTDIAPSR was detected in either the cell or tissue samples alludes to the possibility of other modified forms that were not targeted for these peptides $[19,20]$. The lack of detection of all of the targeted peptides in tissue samples that were previously identified for the same proteins in the cell samples could be the result of modifications present in the biological system. Additionally, for those proteins not detected, explanations could range from an increase in sample complexity (ion suppression from co-eluting species) to an increase in dynamic range of proteins present (low abundance below detection limit of the instrumentation). This is one of the reasons we attempt to track multiple peptides from a single protein. The peptides that were detected in the tissue samples were those that demonstrated the most sensitivity in the cell samples (excluding the XRCC5 peptide HLMLPDFDLLEDIESK).

Fit-for-purpose validation of individual peptides for quantification is arduous and intensive. Characterizing purity, stability, precision, accuracy for multiple peptides exponentially increases the amount of instrument analysis time and expense of starting reagents (i.e., labeled proteins). However, the presented data shows the importance of interrogating these metrics for multiple peptides for a single protein to ensure peptides selected for quantification perform consistently across all types of analyses. Noting the time and resource requirements necessary for validation of multiple target peptides, we have expanded the range of this method 
by using the information from heavily validated peptide targets (XRCC4 peptide ALLSGAGPADVYTFNFSK) to provide relative expression level data about different proteins in the same or similar pathways. This affords us the opportunity to interrogate additional protein expression levels with little added time and expense for reagents. While data gleaned from proteins targeted when no standard was present (XRCC1, 5, 6 and DNA-PK) may not provide absolute protein concentrations, it can provide an estimate of protein expression levels.

There are three reasons for validating XRCC4 in BSA:

- Due to the pharmacology interest [19-20];

- Based on our preliminary data (XRCC4 has a relative lower abundance when compared with other XRCC proteins);

- To utilize validated XRCC4 protein to determine the relative protein expression levels (i.e., XRCCs, DNA-PK) in cancer cells and tissues.

All the factors (i.e., protein digestion efficiency, peptide extraction efficiency, peptide stability, co-elution interference and ionization efficiency/matrix effect of the peptide) have a direct impact on precision (\%CV) and accuracy (\%RE) of the protein quantification; therefore, we applied stable isotope-labeled full-length XRCC4 to minimize sample-processing variations. In addition, we evaluated the peptide stability, precision $(\% \mathrm{CV})$ and accuracy (\%RE) for four peptides in QC samples with BSA. Based on the overall evaluations, the ALLSGAGPADVYTFNFSK peptide for XRCC4 performed the best and used for the protein quantification in the samples from cancer cell lines and tissues. When performing protein quantitation, it is critical to consider that some peptides may be stable (\%Diff) but demonstrate poor accuracy (\%RE) or accurate but not stable such as VENPAEVIR and FILVLNEK, respectively. It is crucial to ensure that the peptides chosen for quantitation perform consistantly for all metrics. This work presents absolute quantification for XRCC4 and rela- tive quantification for additional XRCC protein family members and DNA-PK in human matrices, which is important for a complete understanding of the proteins within the biological context of DNA repair function. Furthermore, it illustrates the rigors with which protein biomarker quantification should be scrutinized. Future directions for MS analysis of XRCC and DNA-PK proteins should include treatment with chemical agents or irraditation to induce DSBs in biological systems. The proper experimental models (nontreated versus DSB-induced) along with a validated protein quantification assay will not only allow for the determination of basal level protein expression, but also help outline thresholds and cut-offs for future use of disease indication in clinical studies. Understanding the concentration ratios of these proteins within a biological system can aid in elucidating the mechanisms by which these proteins carry out DNA repair [35]. In summary, we have developed a robust, multiplex assay to quantitatively assess the protein levels of XRCC1, XRCC4, XRCC5, XRCC6 and DNA-PK with a limit of detection of 0.14 $\mathrm{fmol} / 500 \mathrm{ng}$ total protein with a linearity of 500 -fold in cancer cell lines and human lung and lymphoma cancer tissues. The method has demonstrated the feasibility of applying stable labeled XRCC4 as an IS and the use of high-resolution MS/MS to improve assay accuracy and reproducibility for quantifying the target protein in human matrix.

\section{Future perspective}

The results from protein expression levels in the cancer cells and tumor tissues demonstrated that the methodology (i.e., selected a the isotope-labeled fulllength protein as the IS and evaluate stability, selectivity, linearity, precision and accuracy) is well suited for early stage biomarker identification. As the field progresses, protein markers need to be identified and quantified in multiple matrices (i.e., cells and tissues) to determine their usefulness as clinical biomarkers. Integral to this, the required levels of assay precision for multiplexed LC-MS/MS assays must be established to facilitate analytical support for different sample types

\section{Executive summary}

- The use of isotope-labeled IS is common practice in bioanalytical protein quantification assays. Although other options are available, the use of isotope-labeled full-length protein as IS in LC-MS/MS analysis provides the best analytical specificity for quantifying protein in cancer cells and tumor tissues accounting for sample processing variability.

- A fit-for-purpose method qualification for quantifying XRCC4 in surrogate matrix (bovine serum albumin) was conducted, which established the method stability, selectivity, sensitivity, linearity, accuracy and precision for analysis of XRCCs and DNA-PK in human cancer cells and tumor tissues.

- The protein expression levels for XRCC1, XRCC4, XRCC5, XRCC6 and DNA-PK in HeLa, Ramos and HEK-293 cells and tumor tissues (lung and lymphoma) provide a better understanding of the functional roles these proteins play. 
derived from various matrices (i.e., cells and tumor tissues). At this stage, absolute quantification is not required, but we must be able to measure at least a twofold change for a biomarker with and without treatment. With the great improvement in MS sensitivity (i.e., NanoLC-TripleTOF, NanoLC-OrbitTrap ${ }^{\mathrm{TM}}$ ) during the last few years the gap between ELISA and MS-based assays has narrowed considerably. When one considers the multiplexing capability, uncomplicated by antibody cross reactivity, the MS-based assay will play an important role in biomarker development and, thus, have a large impact for understanding the mechanism of drug action.

\section{Supplementary data}

To view the supplementary data that accompany this paper please visit the journal website at: www.future-science.com/ doi/suppl/10.4155/BIO.14.121

\section{References}

Papers of special note have been highlighted as:

- of interest; $\bullet \bullet$ of considerable interest

1 Durr E, Yu J, Krasinska KM et al. Direct proteomic mapping of the lung microvascular endothelial cell surface in vivo and in cell culture. Nat. Biotechnol. 22(8), 985-992 (2004).

2 Li Y, Yu J, Wang Y et al. Enhancing identifications of lipidembedded proteins by mass spectrometry for improved mapping of endothelial plasma membranes in vivo. Mol. Cell. Proteomics 8(6), 1219-1235 (2009).

3 Oh P, Li Y, Yu J et al. Subtractive proteomic mapping of the endothelial surface in lung and solid tumours for tissuespecific therapy. Nature 429(6992), 629-635 (2004).

4 Oh P, Borgström P, Witkiewicz $\mathrm{H}$ et al. Live dynamic imaging of caveolae pumping targeted antibody rapidly and specifically across endothelium in the lung. Nat. Biotechnol. 25(4), 327-337 (2007).

5 Shiio Y, Donohoe S, Yi EC, Goodlett DR, Aebersold R, Eisenman RN. Quantitative proteomic analysis of Myc oncoprotein function. EMBO J. 21(19), 5088-5096 (2002).

6 Shiio Y, Suh KS, Lee H, Yuspa SH, Eisenman RN, Aebersold R. Quantitative proteomic analysis of myc-induced apoptosis: a direct role for Myc induction of the mitochondrial chloride ion channel, mtCLIC/CLIC4. J. Biol. Chem. 281(5), 27502756 (2006).

7 Chiang MC, Juo CG, Chang HH, Chen HM, Yi EC, Chem Y. Systematic uncovering of multiple pathways underlying the pathology of Huntington disease by an acidcleavable isotope-coded affinity tag approach. Mol. Cell. Proteomics 6(5), 781-797 (2007).

$8 \mathrm{Yu} \mathrm{KH,} \mathrm{Barry} \mathrm{CG,} \mathrm{Austin} \mathrm{D} \mathrm{et} \mathrm{al.} \mathrm{Stable} \mathrm{isotope} \mathrm{dilution}$ multidimensional liquid chromatography-tandem mass spectrometry for pancreatic cancer serum biomarker discovery. J. Proteome Res. 8(3), 1565-1576 (2009).

- Novel paper outlining the use of metabolic labeling to detect and quantify target protein markers in biological matrices.
Financial \& competing interests disclosure MV Myers, SE Maxwell and X Wang are Celgene employees, and as such, have Celgene stock ownership. The authors have no other relevant affiliations or financial involvement with any organization or entity with a financial interest in or financial conflict with the subject matter or materials discussed in the manuscript apart from those disclosed.

No writing assistance was utilized in the production of this manuscript.

\section{Ethical conduct of research}

The authors state that they have obtained appropriate institutional review board approval or have followed the principles outlined in the Declaration of Helsinki for all human or animal experimental investigations. In addition, for investigations involving human subjects, informed consent has been obtained from the participants involved.

9 Ong SE, Blagoev B, Kratchmarova I et al. Stable isotope labeling by amino acids in cell culture, SILAC, as a simple and accurate approach to expression proteomics. Mol. Cell. Proteomics 1 (5), 376-386 (2002).

10 Ong SE, Mann M. A practical recipe for stable isotope labeling by amino acids in cell culture (SILAC). Nat. Protoc. 1(6), 2650-2660 (2006).

11 Wong JW, Sullivan MJ, Cagney G. Computational methods for the comparative quantification of proteins in label-free LCn-MS experiments. Brief Bioinform. 9(2), 156-165 (2008).

12 Yates JR 3rd, Gilchrist A, Howell KE, Bergeron JJ. Proteomics of organelles and large cellular structures. Nat. Rev. Mol. Cell. Biol. 6(9), 702-714 (2005).

13 Griffin NM, Yu J, Long F et al. Label-free, normalized quantification of complex mass spectrometry data for proteomic analysis. Nat. Biotechnol. 28(1), 83-89 (2010).

14 Brun V, Dupuis A, Adrait A et al. Isotope-labeled protein standards: toward absolute quantitative proteomics. Mol. Cell. Proteomics 6(12), 2139-2149 (2007).

-. Provides a comparative analysis of proteins versus peptides as labeled standards for biomarker quantification in biological samples.

15 Diamandis EP. Cancer biomarkers: can we turn recent failures into success? J. Natl Cancer Inst. 102(19), 1462-1467 (2010).

-. Inclusive paper discusing the concepts and hurdles of biomarker validaion for clinical use after discovery.

16 Yocum AK, Yu K, Oe T, Blair IA. Effect of immunoaffinity depletion of human serum during proteomic investigations. J. Proteome Res. 4(5), 1722-1731 (2005).

17 Kuzyk MA, Smith D, Yang J et al. Multiple reaction monitoring-based, multiplexed, absolute quantitation of 45 proteins in human plasma. Mol. Cell. Proteomics 8(8), 1860-1877 (2009). 
- $\quad$ Key paper discussing the use of targeted MS methods to quantify multiple protein targets in single analysis of complex matrix using labeled peptides as IS.

Tomkinson AE, Mackey ZB. Structure and function of mammalian DNA ligases. Mutat. Res. 407(1), 1-9 (1998).

19 Yu Y, Wang W, Ding Q et al. DNA-PK phosphorylation sites in XRCC4 are not required for survival after radiation or for V(D)J recombination. DNA Repair (Amst.) 2(11), 1239-1252 (2003).

- Outlines the interaction between DNA-dependent serine/threonine protein kinase and XRCC4 using mutational analysis and MS. Specific sites of phosphorylation are discussed.

20 Lee KJ, Jovanovic M, Udayakumar D, Bladen CL, Dynan WS. Identification of DNA-PKcs phosphorylation sites in XRCC 4 and effects of mutations at these sites on DNA end joining in a cell-free system. DNA Repair (Amst.) 3(3), 267-276 (2004).

21 Oksenych V, Kumar V, Liu X et al. Functional redundancy between the XLF and DNA-PKcs DNA repair factors in $\mathrm{V}(\mathrm{D}) \mathrm{J}$ recombination and nonhomologous DNA end joining. Proc. Natl Acad. Sci. USA 110(6), 2234-2239 (2013).

22 Improta G, Sgambato A, Bianchino G et al. Polymorphisms of the DNA repair genes XRCC1 and XRCC3 and risk of lung and colorectal cancer: a case-control study in a Southern Italian population. Anticancer Res. 28(5B), 2941-2946 (2008).

23 Cui Z, Yin Z, Li X, Wu W, Guan P, Zhou B. Association between polymorphisms in XRCC1 gene and clinical outcomes of patients with lung cancer: a meta-analysis, $B M C$ Cancer 12(71) 2407-2412 (2012).

24 Goh WW, Lee YH, Zubaidah RM et al. Network-based pipeline for analyzing MS data: an application toward liver cancer. J. Proteome Res. 10(5), 2261-2272 (2011).

25 Metsola K, Kataja V, Sillanpää P et al. XRCC1 and XPD genetic polymorphisms, smoking and breast cancer risk in a Finnish case-control study. Breast Cancer Res. 7(6), 987-997 (2005).

26 Petricoin EF, Ardekani AM, Hitt BA et al. Use of proteomic patterns in serum to identify ovarian cancer. Lancet 359(9306), 572-577 (2002).
27 McLerran D, Grizzle WE, Feng Z et al. SELDI-TOF MS whole serum proteomic profiling with IMAC surface does not reliably detect prostate cancer. Clin. Chem. 54(1), 53-60 (2008).

28 Tonoli D, Varesio E, Hopfgartner G, Quantification of acetaminophen and two of its metabolites in human plasma by ultra-high performance liquid chromatography-low and high resolution tandem mass spectrometry. J. Chromatogr. B 1(904), 42-50 2012).

29 Picotti P, Bodenmiller B, Mueller LN, Domon B, Aebersold R. Full dynamic range proteome analysis of $S$. cerevisiae by targeted proteomics. Cell 138(4), 795-806 (2009).

30 Ebhardt HA, Sabidó E, Hüttenhain R, Collins B, Aebersold $\mathrm{R}$. Range of protein detection by selected/multiple reaction monitoring mass spectrometry in an unfractionated human cell culture lysate. Proteomics 12(98), 1185-1193 (2012).

- Describes the use of scheduled multiple reaction monitoring methods to define a range for all dectable and identifiable proteins in a human cell line. Using the data generated, they calculated upper and lower limit protein copies per cell for unfractionated samples.

31 Beck M, Schmidt A, Malmstroem J et al. The quantitative proteome of a human cell line. Mol. Syst. Biol. 7(549), $1-8(2011)$.

32 Li H, Ortiz R, Tran L et al. General LC-MS/MS method approach to quantify therapeutic monoclonal antibodies using a common whole antibody internal standard with application to preclinical studies. Anal. Chem. 84(3), 12671273 (2012).

33 Li H, Ortiz R, Tran LT et al. Simultaneous analysis of multiple monoclonal antibody biotherapeutics by LC-MS/MS method in rat plasma following cassette-dosing. AAPS J. 15(2), 337-346 (2013).

34 US FDA, Guidance for Industry, Bioanalytical Method Validation, September 2013. www.fda.gov/downloads/Drugs/ GuidanceComplianceRegulatoryInformation/Guidance/ UCM368107.pdf

35 Niu Y, Zhang X, Zheng Y, Zhang R. XRCC1 deficiency increased the DNA damage induced by $\gamma$-ray in HepG2 cell: involvement of DSB repair and cell cycle arrest. Environ. Toxicol. Pharmacol. 36(2), 311-319 (2013). 